\title{
Sustainability in the AAP Bronchiolitis Quality Improvement Project
}

\author{
Kristin A. Shadman, MD ${ }^{1 *}$, Shawn L. Ralston, MD, MS², Matthew D. Garber, MD³, Jens Eickhoff, PhD¹, \\ Grant M. Mussman, MD', Susan C. Walley, MD ${ }^{5}$, Elizabeth Rice-Conboy, $\mathrm{MS}^{6}$, Ryan J. Coller, MD, MPH ${ }^{1}$
}

\begin{abstract}
${ }^{1}$ University of Wisconsin School of Medicine and Public Health, Madison, Wisconsin; ${ }^{2}$ Children's Hospital at Dartmouth, Lebanon, New Hampshire; ${ }^{3}$ University of Florida College of Medicine, Gainesville, Florida; ${ }^{4}$ Cincinnati Children's Hospital Medical Center, Cincinnati, Ohio; ${ }^{5}$ American Academy of Pediatrics, Elk Grove, Illinois; ${ }^{2}$ University of Alabama, Birmingham, Alabama.
\end{abstract}

BACKGROUND AND OBJECTIVES: Adherence to American Academy of Pediatrics (AAP) bronchiolitis clinical practice guideline recommendations improved significantly through the AAP's multiinstitutional collaborative, the Bronchiolitis Quality Improvement Project (BQIP). We assessed sustainability of improvements at participating institutions for 1 year following completion of the collaborative.

METHODS: Twenty-one multidisciplinary hospital-based teams provided monthly data for key inpatient bronchiolitis measures during baseline and intervention bronchiolitis seasons. Nine sites provided data in the season following completion of the collaborative. Encounters included children younger than 24 months who were hospitalized for bronchiolitis without comorbid chronic illness, prematurity, or intensive care. Changes between baseline-, intervention-, and sustainability-season data were assessed using generalized linear mixed-effects models with site-specific random effects. Differences between hospital characteristics, baseline performance, and initial improvement between sites that did and did not participate in the sustainability season were compared.

RESULTS: A total of 2275 discharges were reviewed, comprising 995 baseline, 877 intervention, and 403 sustainability-season encounters. Improvements in all key bronchiolitis quality measures achieved during the intervention season were maintained during the sustainability season, and orders for intermittent pulse oximetry increased from 40.6\% $(95 \%$ confidence interval [Cl], 22.8-61.1) to $79.2 \%(95 \% \mathrm{Cl}, 58.0-$ 91.3). Sites that did and did not participate in the sustainability season had similar characteristics.

DISCUSSION: BQIP participating sites maintained improvements in key bronchiolitis quality measures for 1 year following the project's completion. This approach, which provided an evidence-based best-practice toolkit while building the quality-improvement capacity of local interdisciplinary teams, may support performance gains that persist beyond the active phase of the collaborative. Journal of Hospital Medicine 2017;12:905-910. Published online first September 6, 2017. (C) 2017 Society of Hospital Medicine
Acute viral bronchiolitis is the most common cause of hospitalization for children less than 1 year of age. ${ }^{1}$ Overuse of ineffective therapies has persisted despite the existence of the evidence-based American Academy of Pediatrics (AAP) clinical practice guideline (CPG), which recommends primarily supportive care. ${ }^{2-8}$ Adherence to the AAP CPG recommendations for management of bronchiolitis improved significantly through the AAP's Bronchiolitis Quality Improvement Project (BQIP), a 12-month, multiinstitutional collaborative of community and free-standing children's hospitals. ${ }^{9}$ This subsequent study investigates if these improvements were sustained after completion of the formal 12-month project.

Published multiinstitutional bronchiolitis quality improvement (QI) work is limited to 1 study $^{5}$ that describes the results of a single intervention season at academic med-

\footnotetext{
*Address for correspondence and reprint requests: Kristin A. Shadman, MD, Department of Pediatrics, University of Wisconsin, H4/468 CSC, 600 Highland Ave, Madison, WI 53972; Telephone: 608-265-8561; E-mail: kshadman@ pediatrics.wisc.edu
}

Additional Supporting Information may be found in the online version of this article. Received: January 18, 2017; Revised: April 5, 2017; Accepted: May 6, 2017 2017 Society of Hospital Medicine DOI 10.12788/jhm2830 ical centers. Multiyear bronchiolitis QI projects are limited to single-center studies, and results have been mixed. $5,6,8,10-13$ One study ${ }^{11}$ observed continued improvement in bronchodilator use in subsequent seasons, whereas a second study ${ }^{10} \mathrm{ob}$ served a return to baseline bronchodilator use in the following season. Mittal ${ }^{6}$ observed inconsistent improvements in key bronchiolitis measures during postintervention seasons.

Our specific aim was to assess the sustainability of improvements in bronchiolitis management at participating institutions 1 year following completion of the AAP BQIP collaborative. ${ }^{9}$ Because no studies demonstrate the most effective way to support long-term improvement through a QI collaborative, we hypothesized that the initial collaborative activities, which were designed to build the capacity of local interdisciplinary teams while providing standardized evidence-based care pathways, would lead to performance in the subsequent season at levels similar to or better than those observed during the active phase of the collaborative, without additional project interventions.

\section{METHODS}

\section{Study Design and Setting}

This was a follow-up study of the AAP Quality Improvement Innovation Networks project entitled "A Quality Collaborative for Improving Hospital Compliance with the 
AAP Bronchiolitis Guideline" (BQIP). ${ }^{9}$ The AAP Institutional Review Board approved this project.

Twenty-one multidisciplinary, hospital-based teams participated in the BQIP collaborative and provided monthly data during the January through March bronchiolitis season. Teams submitted 2013 baseline data and 2014 intervention data. Nine sites provided 2015 sustainability data following the completion of the collaborative.

\section{Participants}

Hospital encounters with a primary diagnosis of acute viral bronchiolitis were eligible for inclusion among patients from 1 month to 2 years of age. Encounters were excluded for prematurity $(<35$ weeks gestational age), congenital heart disease, bronchopulmonary dysplasia, genetic, congenital or neuromuscular abnormalities, and pediatric intensive-care admission.

\section{Data Collection}

Hospital characteristics were collected, including hospital type (academic, community), bed size, location (urban, rural), hospital distributions of race/ethnicity and public payer, cases of bronchiolitis per year, presence of an electronic medical record and a pediatric respiratory therapist, and self-rated QI knowledge of the multidisciplinary team (very knowledgeable, knowledgeable, and somewhat knowledgeable). A trained member at each site collected data through structured chart review in baseline, intervention, and sustainability bronchiolitis seasons for January, February, and March. Site members reviewed the first 20 charts per month that met the inclusion criteria or all charts if there were fewer than 20 eligible encounters. Sites input data about key quality measures into the AAP's Quality Improvement Data Aggregator, a web-based data repository.

\section{Intervention}

The BQIP project was designed as a virtual collaborative consisting of monthly education webinars about QI methods and bronchiolitis management, opportunities for collaboration via teleconference and e-mail listserv, and individual site-coaching by e-mail or telephone. ${ }^{9} \mathrm{~A}$ change package was shared with sites that included examples of evidence-based pathways, ordersets, a respiratory scoring tool, communication tools for parents and referring physicians, and slide sets for individual site education efforts. Following completion of the collaborative, written resources remained available to participants, although virtual collaboration ceased and no additional project interventions to promote sustainability were introduced.

\section{Bronchiolitis Process and Outcome Measures}

Process measures following admission included the following: severity assessment using a respiratory score, respiratory score use to assess response to bronchodilators, bronchodilator use, bronchodilator doses, steroid doses per patient encounter, chest radiographs per encounter, and presence of an order to transition to intermittent pulse oximetry monitoring. Outcome measures included length of stay and readmissions within 72 hours.

\section{Analysis}

Changes among baseline-, intervention-, and sustainability-season data were assessed using generalized linear mixed-effects models with random effect for study sites. Negative binomial models were used for count variables to allow for overdispersion. Length of stay was log-transformed to achieve a normal distribution. We also analyzed each site individually to assess whether sustained improvements were the result of broad sustainability across all sites or whether they represented an aggregation of some sites that continued to improve while other sites actually worsened.

To address any bias introduced by the voluntary and incomplete participation of sites in the sustainability season, we planned a priori to conduct 3 additional analyses. First, we compared the characteristics of sites that did participate in the sustainability season with those that did not participate by using Chi-squared tests for differences in proportions and $t$ tests for differences in means. Second, we determined whether the baseline-season process and outcome measures were different between sites that did and did not participate using descriptive statistics. Third, we assessed whether improvements between the baseline and intervention seasons were different between sites that did and did not participate using a linear mixed-effects model for normally distributed outcomes and generalized linear mixed-effects model with site-specific random effects for nonnormally distributed outcomes. All study outcomes were summarized in terms of model-adjusted means along with the corresponding 95\% confidence intervals. All $P$ values are 2 -sided, and $P<0.05$ was used to define statistical significance. Data analyses were conducted using SAS software (SAS Institute Inc., Cary, North Carolina) version 9.4.

\section{RESULTS}

A total of 2275 patient encounters were reviewed, comprising 995 encounters from the baseline season, 877 from the intervention season, and 403 from the sustainability season. Improvements were observed across key bronchiolitis quality measures from the baseline to intervention season, ${ }^{9}$ although not every site improved in every metric. All improvements achieved by the combined groups during the intervention season were sustained during the sustainability season (Table 1). No measures demonstrated statistically significant reductions between the intervention and sustainability seasons, and the use of intermittent pulse oximetry continued to increase. Length of stay and 72-hour readmissions were not statistically different between seasons $(P=$ 0.54 and $P=0.98$, respectively).

Mean use of a respiratory score, which was $6.6 \%(95 \%$ confidence interval $[\mathrm{CI}], 1.8-21.5)$ in the baseline season, increased to $73.9 \%(95 \% \mathrm{CI}, 56.9-85.9)$ during the intervention season and $70.7 \%$ (95 \% CI, 53.8-83.5) in the sustainability season. The number of bronchodilator doses per 
TABLE 1. Differences in Performance of Bronchiolitis QI Measures Following Admission Between Baseline, Intervention and Sustainability Seasons

\begin{tabular}{|c|c|c|c|c|c|c|c|c|c|}
\hline & $\begin{array}{l}\text { Severity } \\
\text { Assessed } \\
\text { using } \\
\text { Respiratory } \\
\text { Score } \\
\% \\
(95 \% \mathrm{Cl})\end{array}$ & $\begin{array}{l}\text { Respiratory Score } \\
\text { Use to Assess } \\
\text { Response to } \\
\text { Bronchodilator \% } \\
\quad(95 \% \mathrm{Cl})\end{array}$ & $\begin{array}{c}\text { Bronchodilator } \\
\text { Use } \\
\% \\
(95 \% \mathrm{Cl})\end{array}$ & $\begin{array}{c}\text { Bronchodilator } \\
\text { Doses / } \\
\text { Encounter } \\
\text { Mean } \\
(95 \% \mathrm{Cl})\end{array}$ & $\begin{array}{l}\text { Steroid Doses } \\
\text { / Encounter } \\
\text { Mean } \\
(95 \% \mathrm{Cl})\end{array}$ & $\begin{array}{c}\text { CXR / } \\
\text { Encounter } \\
\text { Mean } \\
(95 \% \mathrm{Cl})\end{array}$ & $\begin{array}{l}\text { Presence of an } \\
\text { Order to Transi- } \\
\text { tion to } \\
\text { Intermittent Pulse } \\
\text { Oximetry } \\
\% \\
(95 \% \mathrm{Cl})\end{array}$ & $\begin{array}{l}\text { Length } \\
\text { of Stay }\end{array}$ & $\begin{array}{c}\text { Readmitted } \\
\text { Within } 72 \\
\text { Hours } \\
\% \\
(95 \% \mathrm{Cl})\end{array}$ \\
\hline Baseline & $\begin{array}{c}6.6 \\
(1.8-21.5)\end{array}$ & $\begin{array}{c}8.6 \\
(2.4-26.2)\end{array}$ & $\begin{array}{c}45.5 \\
(37.9-53.3)\end{array}$ & $\begin{array}{c}3.1 \\
(2.1-4.4)\end{array}$ & $\begin{array}{c}0.33 \\
(0.23-0.48)\end{array}$ & $\begin{array}{c}0.18 \\
(0.11-0.29)\end{array}$ & $\begin{array}{c}40.6 \\
(22.8-61.1)\end{array}$ & $\begin{array}{c}0.53 \\
(0.35-0.71)\end{array}$ & $\begin{array}{c}2.4 \\
(1.3-4.1)\end{array}$ \\
\hline Intervention & $\begin{array}{c}73.9 \\
(56.9-85.9)\end{array}$ & $\begin{array}{c}68.3 \\
(48.1-83.3)\end{array}$ & $\begin{array}{c}23 \\
(17.0-30.0)\end{array}$ & $\begin{array}{c}1.0 \\
(0.7-1.4)\end{array}$ & $\begin{array}{c}0.04 \\
(0.02-0.11)\end{array}$ & $\begin{array}{c}0.08 \\
(0.06-0.11)\end{array}$ & $\begin{array}{c}68.6 \\
(47.4-84.1)\end{array}$ & $\begin{array}{c}0.37 \\
(0.19-0.55)\end{array}$ & $\begin{array}{c}1.8 \\
(1.0-3.2)\end{array}$ \\
\hline $\begin{array}{l}P \text { Value Baseline to } \\
\text { Intervention }\end{array}$ & $<.01$ & $<.01$ & $<.01$ & $<.01$ & $<.01$ & $<.01$ & $<.01$ & $<.01$ & .51 \\
\hline Sustainability & $\begin{array}{c}70.7 \\
(53.8-83.5)\end{array}$ & $\begin{array}{c}57.6 \\
(37.9-75.1)\end{array}$ & $\begin{array}{c}26.1 \\
(19.6-33.8)\end{array}$ & $\begin{array}{c}0.8 \\
(0.5-1.3)\end{array}$ & $\begin{array}{c}0.10 \\
(0.04-0.24)\end{array}$ & $\begin{array}{c}0.07 \\
(0.04-0.15)\end{array}$ & $\begin{array}{c}79.2 \\
(58.0-91.3)\end{array}$ & $\begin{array}{c}0.40 \\
(0.22-0.58)\end{array}$ & $\begin{array}{c}1.7 \\
(1.0-3.6)\end{array}$ \\
\hline $\begin{array}{l}\text { Change from } \\
\text { Intervention to } \\
\text { Sustainability }\end{array}$ & $\begin{array}{c}-3.3 \\
(-9.1-2.7)\end{array}$ & $\begin{array}{c}-10.8 \\
(-23.3-1.8)\end{array}$ & $\begin{array}{c}3.1 \\
(-3.1-9.3)\end{array}$ & $\begin{array}{c}-0.2 \\
(-0.7-0.3)\end{array}$ & $\begin{array}{c}0.05 \\
(-0.04-0.14)\end{array}$ & $\begin{array}{c}0.00 \\
(-.05-0.05)\end{array}$ & $\begin{array}{c}10.7 \\
(-5.0-16.4)\end{array}$ & $\begin{array}{c}0.03 \\
(-0.07-0.13)\end{array}$ & $\begin{array}{c}0.0 \\
(-2.0-2.1)\end{array}$ \\
\hline $\begin{array}{l}P \text { Value Intervention } \\
\text { to Sustainability }\end{array}$ & .26 & .09 & .3 & .5 & .21 & .84 & $<.01$ & .54 & .98 \\
\hline
\end{tabular}

aLog transformed length of stay in days.

NOTE: Abbreviations: Cl, confidence interval; CXR, chest radiograph.

encounter decreased from 3.1 (95\% CI, 2.1-4.4) in the baseline season to $1.0(95 \% \mathrm{CI}, 0.7-1.4)$ in the intervention season and 0.8 (95\% CI, 0.5-1.3) in the sustainability season. Orders for intermittent pulse oximetry increased significantly from a baseline of $40.6 \%$ (95\% CI, 22.8-61.1) to $68.6 \%$ (95\% CI, 47.4-84.1) in the intervention season and $79.2 \%$ (95\% CI, 58.0-91.3) in the sustainability season. In general, this same pattern was present, ie, individual sites did not demonstrate significant improvement or worsening across the measures (Appendix 1a). The Figure illustrates individual site and overall project performance over the study period using bronchodilator use as a representative example.

Characteristics of sites that did and did not participate in the sustainability season were not significantly different (Table 2). The majority of sites were medium-sized centers that cared for an average of 100 to 300 inpatient cases of bronchiolitis per year and were located in an urban environment.

Differences in baseline bronchiolitis quality measures between sites that did and did not participate in the sustainability season are displayed in Table 3 . Sustainability sites had significantly lower baseline use of a respiratory score, both to assess severity of illness at any point after hospitalization as well as to assess responsiveness following bronchodilator treatments $(P<0.001)$. At baseline they also had fewer orders for intermittent pulse oximetry use $(P=0.01)$ and fewer doses of bronchodilators per encounter $(P=0.04)$. Sites were not significantly different in their baseline use of bronchodilators, oral steroid doses, or chest radiographs. Sites that participated in the sustainability season demon-

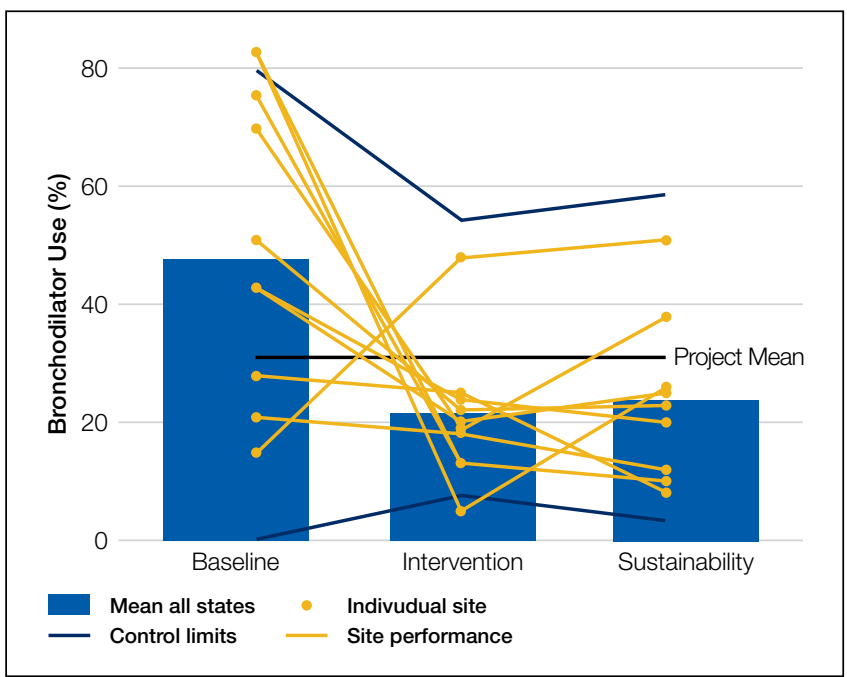

FIG. Individual site performance of bronchodilator use after hospital admission over baseline, intervention and sustainability time periods.

NOTE: Control limits are 2 standard deviations from the project mean.

stated larger magnitude improvement between baseline and intervention seasons for respiratory score use $(P<0.001$ for any use and $P=0.02$ to assess bronchodilator responsiveness; Appendix 1b).

\section{DISCUSSION}

To our knowledge, this is the first report of sustained improvements in care achieved through a multiinstitutional 
TABLE 2. Characteristics of Sites that Did and Did Not Participate in the BQIP Sustainability Data Collection Season

\begin{tabular}{|c|c|c|c|c|}
\hline \multicolumn{2}{|c|}{ Characteristics of Sites } & $\begin{array}{l}\text { Sustaining Site } \\
\qquad(\mathrm{n}=9) \\
\%\end{array}$ & $\begin{array}{c}\text { Nonsustaining Site } \\
\qquad \begin{array}{c}(\mathrm{n}=12) \\
\%\end{array}\end{array}$ & $P$ Value \\
\hline \multirow[t]{2}{*}{ Hospital Type } & Academic & 67 & 58 & .99 \\
\hline & Community & 33 & 42 & \\
\hline \multirow[t]{3}{*}{ Bed Size } & $\geq 50$ & 11 & 17 & .60 \\
\hline & $10-50$ & 0 & 17 & \\
\hline & $<10$ & 89 & 67 & \\
\hline \multirow[t]{2}{*}{ Hospital Location } & Urban & 67 & 58 & .99 \\
\hline & Suburban & 33 & 42 & \\
\hline \multirow{3}{*}{$\begin{array}{l}\text { Racial/Ethnic Distribution } \\
\text { of Hospital Populationa }\end{array}$} & White, non-Hispanic & 58.6 & 35.4 & .06 \\
\hline & Hispanic & 19.1 & 25.8 & .19 \\
\hline & Black, non-Hispanic & 15.4 & 28.2 & .07 \\
\hline *Public-Insurance Distribution of Hospital Population ${ }^{\mathrm{a}}$ & Public Insurance & 60.9 & 57.6 & .67 \\
\hline Presence of EHR & Yes & 100 & 83 & .84 \\
\hline \multirow[t]{3}{*}{ Annual Cases of Bronchiolitis } & $\geq 300$ & 22 & 8 & .84 \\
\hline & $100-300$ & 44 & 42 & \\
\hline & $<100$ & 33 & 50 & \\
\hline Presence of Pediatric RT & Yes & 66 & 92 & .27 \\
\hline \multirow[t]{3}{*}{ Ql Knowledge, self-rated } & Very Knowledgeable & 11 & 17 & .84 \\
\hline & Knowledgeable & 56 & 33 & \\
\hline & Somewhat & 33 & 50 & \\
\hline
\end{tabular}

aThese proportions reflect the hospital's self-reported distribution of race/ethnicity and public-payer status and not necessarily the distributions of encounters included in the Bronchiolitis Quality Improvement Project (BQIP) collaborative. NOTE: Abbreviations: BQIP, Bronchiolitis Quality Improvement Project; EHR, electronic health record; RT, respiratory therapist; QI, quality improvement.

QI collaborative of community and academic hospitals focused on bronchiolitis care. We found that overall sites participating in a national bronchiolitis QI project sustained improvements in key bronchiolitis quality measures for 1 year following the project's completion. For the aggregate group no measures worsened, and one measure, orders for intermittent pulse oximetry monitoring, continued to increase during the sustainability season. Furthermore, the sustained improvements were primarily the result of consistent sustained performance of each individual site, as opposed to averages wherein some sites worsened while others improved (Appendix 1a). These findings suggest that designing a collaborative approach, which provides an evidence-based best-practice toolkit while building the QI capacity of local interdisciplinary teams, can support performance gains that persist beyond the project's active phase.

There are a number of possible reasons why improvements were sustained following the collaborative. The BQIP requirement for institutional leadership buy-in may have motivated accountability to local leaders in subsequent bronchiolitis seasons at each site. We suspect that culture change such as flattened hierarchies through multidisciplinary teams, ${ }^{14}$ which empowered nurse and respiratory therapy staff, may have facilitated consistent use of tools created locally. The synergy of interdisciplinary teams composed of physician, nurse, and respiratory therapy champions may have created accountability to perpetuate the previous year's efforts. ${ }^{15}$ In addition, the sites adopted elements of the evidence-based toolkit, such as pathways, ${ }^{16,17}$ forcing function tools ${ }^{13,18}$ and order sets that limited management decision options and bronchodilator use contingent on respiratory scores, ${ }^{9,19}$ which may have driven desired behaviors.

Moreover, the 2014 AAP CPG for the management of bronchiolitis, ${ }^{20}$ released prior to the sustainability bronchiolitis season, may have underscored the key concepts of the collaborative. Similarly, national exposure of best practices for bronchiolitis management, including the 3 widespread Choosing Wisely recommendations related to bronchiolitis, ${ }^{21}$ might have been a compelling reason for sites to maintain their improvement efforts and contribute to secular trends toward decreasing interventions in bronchiolitis management nationally. ${ }^{3}$ Lastly, the mechanisms developed for local data collection may have created opportunities at each site to conduct ongoing evaluation of performance on key bronchiolitis quality measures through data-driven feedback systems. ${ }^{22}$ Our study highlights the need for additional research in order to understand why improvements are or are not sustained.

Even with substantial, sustained improvements in this initiative, further reduction in unnecessary care may be possible. Findings from previous studies suggest that even 
TABLE 3. Differences in Bronchiolitis Quality Measures at Baseline for Sites that Did and Did Not Participate in BQIP Sustainability Data Collection Season

\begin{tabular}{lccc}
\hline Bronchiolitis Quality Measure & $\begin{array}{c}\text { Sustaining Site } \\
(\mathrm{n}=9)\end{array}$ & $\begin{array}{c}\text { Nonsustaining Site } \\
(\mathrm{n}=12)\end{array}$ & 35.2 \\
\hline Severity Assessed Using Respiratory Score, $\%$ & 5.4 & 23.2 & $<.2$ \\
\hline Respiratory Score Use to Assess Response to Bronchodilator, \% & 7.7 & 47.6 & .001 \\
\hline Bronchodilator Use, $\%$ & 45.7 & 4.0 & .54 \\
\hline Bronchodilator Doses/Encounter, Mean & 3.1 & 0.4 & .04 \\
\hline Steroids Doses/Encounter, mean & 0.3 & 0.14 \\
\hline CXR/Encounter, Mean & 0.18 & 47.6 \\
\hline Presence of an Order to Transition to Intermittent Pulse Oximetry, \% & 39.7 & .93 \\
\hline NOTE: Abbreviations: BQIP, Bronchiolitis Quality Improvement Project; CXR, chest radiograph. & & .01 \\
\hline
\end{tabular}

multifaceted QI interventions, including provider education, guidelines and use of respiratory scores, may only modestly reduce bronchodilators, steroids, and chest radiograph use. ${ }^{8,13}$ To achieve continued improvements in bronchiolitis care, additional active efforts may be needed to develop new interventions that target root causes for areas of overuse at individual sites.

Future multiinstitutional collaboratives might benefit their participants if they include a focus on helping sites develop skills to ensure that local improvement activities continue after the collaborative phases are completed. Proactively scheduling intermittent check-ins with collaborative members to discuss experiences with both sustainability and ongoing improvement may be valuable and likely needs to be incorporated into the initial collaborative planning.

As these sustainability data represent a subset of 9 of the original $21 \mathrm{BQIP}$ sites, there is concern for potential selection bias related to factors that could have motivated sites to participate in the sustainability season's data collection and simultaneously influenced their performance. These concerns were mitigated to some extent through 3 specific analyses: finding limited differences in hospital characteristics, baseline performance in key bronchiolitis measures, and performance change from baseline to intervention seasons between sites that did and did not participate in the sustainability season.

Notably, sites that participated in the sustainability phase actually had lower baseline respiratory score use and fewer orders for intermittent pulse oximetry at baseline. Theoretically, if participation in the collaborative highlighted this disparity for these sites, it could have been a motivating factor for their continued participation and sustained performance across these measures. Similarly, sites that recognized their higher baseline performance through participation in the collaborative might have felt less motivation to participate in ongoing data collection during the sustainability season. Whether they might have also sustained, declined, or continued improving is not known. Additionally, the mag- nitude of improvement in the collaborative period might have also motivated ongoing participation during the sustainability phase. For example, although all sites improved in score use during the collaborative, sites participating in the sustainability season demonstrated significantly more improvement in these measures. Sites with a higher magnitude of improvement in collaborative measures might have more enthusiasm about the project, more commitment to the project activities, or feel a sense of obligation to respond to requests for additional data collection.

This work has several limitations. Selection bias may limit generalizability of the results, as sites that did not participate in the sustainability season may have had different results than those that did participate. It is unknown whether sites that regressed toward their baseline were deterred from participating in the sustainability season. The analyses that we were able to preform, however, suggest that the 2 groups were similar in their characteristics as well as in their baseline and improvement performance.

We have limited knowledge of the local improvement work that sites conducted between the completion of the collaborative and the sustainability season. Site-specific factors may have influenced improvement sustainability. For example, qualitative research with the original group found that team engagement had a quantitative association with better performance, but only for the bronchodilator use measure. ${ }^{23}$ Sites were responsible for their own data collection, and despite attempts to centralize and standardize the process, data collection inconsistencies may have occurred. For instance, it is unknown how closely that orders for intermittent pulse oximetry correlate with intermittent use at the bedside. Lastly, the absence of a control group limits examination of the causal relationships of interventions and the influence of secular trends.

\section{CONCLUSIONS}

Improvements gained during the BQIP collaborative were sustained at 1 year following completion of the collabora- 
tive. These findings are encouraging, as national QI collaborative efforts are increasingly common. Our findings suggest that opportunities exist to even further reduce unnecessary care in the management of bronchiolitis. Such opportunities highlight the importance of integrating strategies to both measure sustainability and plan for ongoing independent local activities after completion of the collaborative. Future efforts should focus on supporting local sites to continue individual practice-improvement as they transition from collaborative to independent quality initiatives.

\section{Acknowledgments}

The authors thank the 21 hospitals that participated in the BQIP collaborative, and in particular the 9 hospital teams that contributed sustainability data for their ongoing dedication. There was no external funding for this manuscript.

Disclosure: The authors report no financial conflicts of interest.

\section{References}

1. Healthcare Cost and Utilization Project (HCUP) KID Trends Supplemental File. Agency for Healthcare Research and Quality website. http://hcupnet.ahrq.gov/ HCUPnet.jsp?Id=2C331B13FB40957D\&Form=DispTab\&JS=Y\&Action=Ac cept. 2012. Accessed July 21, 2016

2. Ralston S, Parikh K, Goodman D. Benchmarking overuse of medical interventions for bronchiolitis. JAMA Pediatr. 2015;169:805-806.

3. Parikh K, Hall M, Teach SJ. Bronchiolitis management before and after the AAP guidelines. Pediatrics. 2014;133:e1-e7.

4. Johnson LW, Robles J, Hudgins A, Osburn S, Martin D, Thompson A. Management of bronchiolitis in the emergency department: impact of evidence-based guidelines? Pediatrics. 2013;131 Suppl 1:S103-S109.

5. Kotagal UR, Robbins JM, Kini NM, Schoettker PJ, Atherton HD, Kirschbaum MS. Impact of a bronchiolitis guideline: a multisite demonstration project. Chest. 2002;121:1789-1797.

6. Mittal V, Darnell C, Walsh B, et al. Inpatient bronchiolitis guideline implementation and resource utilization. Pediatrics. 2014;133:e730-e737.

7. Mittal V, Hall M, Morse R, et al. Impact of inpatient bronchiolitis clinical practice guideline implementation on testing and treatment. J Pediatr. 2014;165: 570.e3-576.e3.
8. Ralston S, Garber M, Narang S, et al. Decreasing unnecessary utilization in acute bronchiolitis care: results from the value in inpatient pediatrics network. J Hosp Med. 2013;8:25-30

9. Ralston SL, Garber MD, Rice-Conboy E, et al. A multicenter collaborative to reduce unnecessary care in inpatient bronchiolitis. Pediatrics. 2016;137.

10. Perlstein PH, Kotagal UR, Schoettker PJ, et al. Sustaining the implementation of an evidence-based guideline for bronchiolitis. Arch Pediatr Adolesc Med. 2000;154:1001-1007.

11. Walker C, Danby S, Turner S. Impact of a bronchiolitis clinical care pathway on treatment and hospital stay. Eur J Pediatr. 2012;171:827-832.

12. Cheney J, Barber S, Altamirano L, et al. A clinical pathway for bronchiolitis is effective in reducing readmission rates. J Pediatr. 2005;147:622-626.

13. Ralston S, Comick A, Nichols E, Parker D, Lanter P. Effectiveness of quality improvement in hospitalization for bronchiolitis: a systematic review. Pediatrics. 2014;134:571-581.

14. Schwartz RW, Tumblin TF. The power of servant leadership to transform health care organizations for the 21st-century economy. Arch Surg. 2002;137:1419-1427; discussion 27.

15. Schalock RL, Verdugo M, Lee T. A systematic approach to an organization's sustainability. Eval Program Plann. 2016;56:56-63.

16. Wilson SD, Dahl BB, Wells RD. An evidence-based clinical pathway for bronchiolitis safely reduces antibiotic overuse. Am J Med Qual. 2002;17:195-199.

17. Muething S, Schoettker PJ, Gerhardt WE, Atherton HD, Britto MT, Kotagal UR. Decreasing overuse of therapies in the treatment of bronchiolitis by incorporating evidence at the point of care. J Pediatr. 2004;144:703-710.

18. Streiff MB, Carolan HT, Hobson DB, et al. Lessons from the Johns Hopkins multi-disciplinary venous thromboembolism (VTE) prevention collaborative. BMJ. 2012;344:e3935.

19. Todd J, Bertoch D, Dolan S. Use of a large national database for comparative evaluation of the effect of a bronchiolitis/viral pneumonia clinical care guideline on patient outcome and resource utilization. Arch Pediatr Adolesc Med. 2002;156:1086-1090.

20. Ralston SL, Lieberthal AS, Meissner HC, et al. Clinical practice guideline: the diagnosis, management, and prevention of bronchiolitis. Pediatrics. 2014;134:e1474-e1502.

21. Quinonez RA, Garber MD, Schroeder AR, et al. Choosing wisely in pediatric hospital medicine: five opportunities for improved healthcare value. J Hosp Med. 2013;8:479-485.

22. Stone S, Lee HC, Sharek PJ. Perceived factors associated with sustained improvement following participation in a multicenter quality improvement collaborative. Jt Comm J Qual Patient Saf. 2016;42:309-315.

23. Ralston SL, Atwood EC, Garber MD, Holmes AV. What works to reduce unnecessary care for bronchiolitis? A qualitative analysis of a national collaborative. Acad Pediatr. 2017;17(2):198-204. 